Retraction

\title{
Retraction Note: Isolation of Lactobacillus Species from Domestic Dairy Products of Mahabad City
}

\author{
Masoud Salehi ${ }^{1, *}$ \\ ${ }^{1}$ Infectious Diseases and Tropical Medicine Research Center, Zahedan University of Medical Sciences, Zahedan, IR Iran \\ Received 2019 August 06; Accepted 2019 August 11. \\ This retracts the article "Retracted Article: Isolation of Lactobacillus Species from Domestic Dairy Products of Mahabad City".
}

"Corresponding author: Infectious Diseases and Tropical Medicine Research Center, Zahedan University of Medical Sciences, Zahedan, IR Iran Email: shahestan@gmail.com

This article [ID: 62152] has been retracted by the Editor-in-Chief on the grounds of professional misconduct. Due to the publication of the article by the supervisor without the knowledge of a college student, this article is retracted.

The Editorial Office apologizes to the readers for any inconvenience it may have caused. 